Temperament, family environment and anxiety in preschool children.

Running head: $\mathrm{BI}$, family environment and anxiety

Jennifer L. Hudson, Helen F. Dodd, Nataly Bovopoulos

Centre for Emotional Health, Macquarie University.

Corresponding author.

Jennifer L Hudson, Ph.D.

Centre for Emotional Health

Macquarie University

NSW 2109 AUSTRALIA

jennie.hudson@mq.edu.au (email)

$+61298508668(\mathrm{ph})$

+61298508062 (fax)

This project was supported by the Australian Research Council Discovery Grant (DP0342793).

Acknowledgements: Thank you to the following research assistants and students who assisted in the data collection and coding for this project: Ruth Locker; Natalie Gar; Delyse Hutchinson; Tania Trapolini; Elizabeth Seeley; Heidi Lyneham; Ivone Rebelo; Matthew Horne; Kirsteen Moss; Katy Vidler, Rachel Smith and to the numerous undergraduate volunteers who assisted in the data collection. Thank you also to Alan Taylor for his statistical advice. 


\begin{abstract}
This research examines the relationship between behavioural inhibition (BI), family environment (overinvolved and negative parenting, parental anxiety and parent-child attachment) and anxiety in a sample of 202 preschool children. Participants were aged between 3 years 2 months and 4 years 5 months, 101 were male. A thorough methodology was used that incorporated data from multiple observations of behaviour, diagnostic interviews and questionnaire measures. The results showed that children categorised as behaviourally inhibited were significantly more likely to meet criteria for a range of anxiety diagnoses. Furthermore, a wide range of family environment factors, including maternal anxiety, parenting and attachment were significantly associated with $\mathrm{BI}$, with inhibited children more likely to experience adverse family environment factors. No interactions between temperament and family environment were found for child anxiety. However, a significant relationship between current maternal anxiety and child anxiety was found consistently even after controlling for BI. Additionally, there was some evidence of a relationship between maternal negativity and child anxiety, after controlling for BI. The results may suggest that temperament and family environment operate as additive, rather than interactive risk factors for child anxiety. This is discussed in the context of theoretical models of child anxiety and directions for future research.
\end{abstract}

Keywords: Anxiety, Parenting, Parental Anxiety, Attachment, Behavioural Inhibition. 
Anxiety disorders are amongst the most common form of psychopathology in children and adolescents (Costello, Mustillo, Erkanli, Keeler, \& Angold, 2003). Despite increased attention aimed at the treatment of childhood anxiety and the well-documented efficacy of such treatments (Cartwright-Hatton, Roberts, Chitsabesan, Fothergill, \& Harrington, 2004), research into the causes and prevention of these disorders remains relatively scarce. One factor that has been clearly identified as an early risk factor for the development of anxiety disorders is temperament style Behavioural Inhibition (BI). Kagan has defined $\mathrm{BI}$ in terms of reactions of withdrawal, wariness, avoidance and shyness in novel, unfamiliar situations (Garcia-Coll, Kagan, \& Reznick, 1984). It is estimated that roughly $15 \%$ of infants in the general population are behaviourally inhibited (Fox, Henderson, Marshall, Nichols, \& Ghera, 2005) and that BI is moderately heritable with around $50 \%-80 \%$ of the variance accounted for by genes (Dilalla, Kagan, \& Reznick, 1994).

Several studies report that early BI is associated with increased risk for anxiety disorders, particularly social anxiety disorder, later in life (Chronis-Tuscano et al., 2009; Schwartz, Snidman, \& Kagan, 1999). Importantly, however, not all temperamentally vulnerable children develop an anxiety disorder (Prior, Smart, Sanson, \& Oberklaid, 2000). Consequently, etiological models of childhood anxiety (Hudson \& Rapee, 2004; Vasey \& Dadds, 2001) and recent reviews of the literature (Degnan, Almas, \& Fox, 2010) have stressed the importance of considering the interplay between child temperament and environmental risk factors in order to better understand the development of anxiety in children.

Given that the family context is an important environmental factor in young children's lives, a number of researchers have explored the role of family factors in the development of child anxiety including: parental overcontrol/overinvolvement (Hudson \& 
Rapee, 2001), parental negativity (Barrett, Fox, \& Farrell, 2005), parental anxiety

(Biederman et al., 2001) and parent-child attachment (Moss et al., 2006). In the present research the relationship between each of these family environment factors, $\mathrm{BI}$ and anxiety will be examined with a specific focus on whether these risk factors interact to affect anxiety or operate as additive risk factors.

\section{Parenting styles}

Traditional conceptualisations of parenting focused on the dimensions of acceptance versus rejection and control verses autonomy granting, with acceptance and autonomy granting considered optimal parenting (Rapee, 1997). More recent research has examined parenting styles within this framework. Across this literature, a plethora of terms and corresponding definitions have been used. For example, in relation to the rejection dimension, research has used terms such as negativity, lack of warmth, and hostility. In relation to the control dimension, the terms overprotection, overinvolvement, oversolicitousness and intrusiveness have been used. In the present paper, the terms negativity and overinvolvement are used. Negativity is conceptualised as parenting that is higher in criticism and lower in warmth. It is hypothesized that parents who are negative during interactions with their child may criticise and minimise the child's feelings, undermining the child's emotion regulation and increasing their sensitivity to anxiety (Wood, McLeod, Sigman, Hwang, \& Chu, 2003). Overinvolvement is conceptualised as parenting behaviour that provides more assistance and help to the child than needed, overprotecting the child from potential danger or distress. This behaviour is often intrusive in nature and controlling. Overinvolved parenting is hypothesised to affect child anxiety by increasing the child's perception of threat, reducing the child's perceived control over threat and increasing the child's avoidance of threat (Rapee, 1997). 


\section{Overinvolvement.}

There is consistent evidence from observation research that parents of anxious children are more overinvolved during interactions with their children than parents of nonanxious children (Hudson \& Rapee, 2001; van der Bruggen, Stams, \& Bogels, 2008). Furthermore, longitudinal research suggests that overinvolvement may play a role in the development of anxiety over time (Lieb et al., 2000). Similarly, two studies have shown that overinvolved parenting is associated with subsequent anxiety in preschool children (Bayer, Sanson, \& Hemphill, 2006; Edwards, Rapee, \& Kennedy, 2010). Importantly, there is also a growing body of research showing that overinvolved parenting is associated with the maintenance of $\mathrm{Bl}$ and social reticence in childhood (Degnan et al., 2008; Rubin, Burgess \& Hastings, 2002).

\section{Parental Negativity.}

Although some detailed observation studies have shown that parents of anxious children are more negative during interactions with their child than parents of control children (Barrett et al., 2005), in general the evidence that negativity plays a role in the development of child anxiety is less convincing than for overinvolvement (McLeod, Wood, \& Weisz, 2007). Limited longitudinal research has been conducted and to date findings are inconclusive with some studies reporting significant associations between negativity and anxiety over time (Lieb et al., 2000) and others finding no association (Bayer et al., 2006).

\section{Parental Anxiety}

It is well-established that anxiety runs in families; anxious parents are more likely to have an anxious child (Biederman et al., 2001) and anxious children are more likely than non-anxious children to have an anxious parent (Cooper, Fearn, Willetts, Seabrook, \& Parkinson, 2006). However, the transmission of anxiety from parent to child is likely to be 
more than the transmission of genetic material. Anxious parents may model anxious behaviour (Murray et al., 2008), may provide threat information to their child (Field, Lawson, \& Banerjee, 2008) or encourage avoidant responses to threat (Barrett, Rapee, Dadds, \& Ryan, 1996). Consequently, having an anxious parent can be considered an environmental, as well as a genetic risk factor for child anxiety.

\section{Attachment}

Finally, parent-child attachment has also been identified as a risk factor for the development of anxiety disorders. A recent review of the literature concluded that attachment security in general and ambivalent attachment and disorganised attachment, more specifically, may act as risk factors for anxiety (Brumariu \& Kerns, 2010). For example, Moss et al. (2006) found that children who were classified as having disorganised attachment at age 5-7 years exhibited significantly more anxiety symptoms two years later.

\section{Family Environment, BI and Anxiety}

From this brief overview of the literature it can be seen that, along with $\mathrm{BI}$, a number of family environment factors are associated with the development of child anxiety. Importantly, there is also some indication that children high in $\mathrm{BI}$ are more likely to experience these adverse family environments. For example, children classified as high on $\mathrm{BI}$ are more likely to have anxious an parent (Biederman et al., 1993; Hirshfeld-Becker et al., 2004; Rosenbaum et al., 1992), more likely to have an insecure-ambivalent attachment style (Shamir-Essakow, Ungerer, \& Rapee, 2005), more likely to experience maternal negativity (Hirshfeld-Becker, Biederman, Brody, \& Faraone, 1997) and less likely to be encouraged to be independent (Rubin, Nelson, Hastings, \& Asendorpf, 1999). It is essential therefore that research examining the developmental psychopathology of child anxiety consider the interplay between temperament and family environment factors. 
There are a number of ways in which $\mathrm{BI}$ and family environment might be associated with anxiety risk. First, family environment factors may not be significantly associated with child anxiety once temperament is controlled. Second, family environment factors might represent an additive risk for anxiety, over and above child temperament. Third, family environment factors might interact with temperament such that adverse family environment may have a greater impact on an inhibited child than an uninhibited child. In this way family environment would be conceptualised as a moderator of the child temperament - anxiety relationship. Finally, it has also been proposed that family environment might mediate the relationship between temperament and child anxiety (Degnan et al., 2010). For example, temperament might lead to more overinvolved parenting which might, in turn, lead to increased anxiety. Examination of mediation necessitates longitudinal research, preferably with three time points (Maxwell \& Cole, 2007).

To examine the interplay between temperament and environment, recent research has begun to examine multiple family environment risk factors alongside BI. To date, there is little evidence to suggest that $\mathrm{BI}$ and family environment interact to affect anxiety risk. Instead, additive effects have been reported for attachment, maternal anxiety and $\mathrm{BI}$ (Shamir-Essakow et al., 2005) and for attachment, maternal overinvolvement and BI (van Brakel, Muris, Bogels \& Thomassen, 2006) in cross-sectional research, and for $\mathrm{BI}$ and maternal anxiety (Muris, van Brakel, Arntz \& Schouten, 2010) and BI, child anxiety, maternal negative affect and maternal overinvolvement (Edwards et al., 2010) in longitudinal research. There is, however, some evidence to suggest that BI interacts with overinvolved parenting to affect child temperament and shyness over time (Degnan et al., 2008; Muris et al., 2010; Rubin et al., 2002). 


\section{Summary and Hypotheses}

In summary, although research has established that $\mathrm{BI}$ and family environment are associated with child anxiety, research including multiple risk factors remains scarce (Degnan et al., 2010). Furthermore, with the notable exception of the cross-sectional study by Shamir-Essakow et al. (2005), previous research examining multiple risk factors has relied on questionnaire measures of temperament, family environment and anxiety. There are a number of problems with relying on questionnaire measures. Most pertinent is that when several measures are completed by the same individual, shared method variance can lead to biased estimates of the relationship between the variables assessed. The purpose of the current study was, therefore, to examine the interactive and additive effects of BI and family environment (overinvolvement and negativity, parental anxiety and parent-child attachment) in relation to concurrent anxiety disorders and symptoms in a sample of preschool children using a thorough methodology. Both parent and child anxiety were assessed using structured diagnostic interviews and questionnaire measures, $\mathrm{Bl}$ is assessed using both observation and parent-report questionnaires and multiple observations of parent-child interactions were used to assess parenting factors and attachment. This is the first study to examine this range of risk factors using observation and clinical assessments. Based on previous research and theoretical models, it was hypothesised that: (1) behaviourally inhibited children would have a higher rate of anxiety diagnoses overall and in particular social anxiety disorder; (2) behaviourally inhibited children would be more likely to have anxious parents, more likely to experience overinvolved and negative parenting and more likely to have an insecure-ambivalent attachment style. The additive versus interactive effects of $\mathrm{BI}$ and family environment in relation to anxiety diagnoses and symptoms were 
examined. As limited previous research has explored this research question, no a priori hypotheses were formed.

\section{Method}

\section{Participants}

Participants were 202 children and their parents, recruited as part of a longitudinal study. Participants were recruited through local preschools and via an advertisement in a free parenting magazine. Mothers were invited to complete the Short Temperament Scale for Children (STSC; Sanson, Smart, Prior, Oberklaid, \& Pedlow, 1994) which contains 30 items assessing four temperament dimensions: Approach (tendency to approach versus withdraw from novel situations and people), Inflexibility, Persistence, and Rhythmicity. The STSC has adequate validity, good internal consistency and reliability (e.g., Sanson et al., 1994). In the current screening sample, the internal consistency for the approach scale was Cronbach alpha $=.92$. A total of 2182 screening questionnaires were distributed and 567 (26\%) were returned. Children scoring one standard deviation above or below the normative mean on the Approach Scale were classified as behaviourally inhibited or behaviourally uninhibited respectively $(\mathrm{N}=317)$. These participants were then invited to participate in the full study and 202 (64\%) agreed; 102 classified as high on BI (BI group) and 100 classified as low on BI (BUI group). Children with a developmental disorder or with parents who were unable to read a standard English newspaper were excluded from the study.

The final sample included children aged between 3 years 2 months and 4 Years 5 months (mean $=4$ years, $s d=4$ months). There were an equal number of boys and girls in both temperament groups, $60 \%$ of the children were first born and the majority had one or more siblings (85\%). Of the final sample, $89 \%$ came from two-parent homes, $56 \%$ were from 
middle to high income families. Mothers were aged between 20 and 50 years ( mean $=36.28$ years, $s d=4.47$ years). The majority of mothers (50\%) stayed at home by choice, $42 \%$ worked part-time; $92 \%$ of mothers had completed school up to the age of 18 (92\%) and 85\% had obtained a post-school qualification. For ethnicity, $64 \%$ of participants were identified as being Oceanic, $20 \%$ as European and $10 \%$ as Asian, with the remainder being American, African or Middle Eastern. There were no significant differences between temperament groups for child age, maternal age, education, marital status, family income, number of siblings or birth order $(p>.05)$. Significant differences were found for ethnicity, $\chi^{2}(5)=$ 11.87, $p=.04$, with greater numbers of children of Asian ethnicity in the BI group. Thus, a dummy variable for Asian ethnicity was added as a covariate in all analyses involving comparisons of the temperament groups.

Fathers were also asked to complete a single questionnaire measure of anxiety symptoms. Completed questionnaires were received from 186 fathers. Of the fathers that did not return the questionnaire $69 \%$ were from single-parent or blended families where contact with the father was minimal.

\section{Measures}

Observed behavioural inhibition. In addition to the STSC, BI was assessed using observation of performance on a series of laboratory tasks (Kagan, Reznick, \& Gibbons, 1989). In the first session participants were exposed to: a new room, a novel toy; a masked experimenter dressed in a strange suit. In the second session, conducted on a different day, participants were assessed during a 10 minute period of free play with a same-sex unfamiliar peer. Behaviours used to determine inhibition status included i) time spent proximal to the mother, ii) amount of time staring at the peer, iii) time spent talking, iv) number of approaches to the stranger and v) number of approaches to the peer. A 
participant was defined as behaviorally inhibited, based on observation, if they scored above the cutoff on three or more of these five behaviours. The cutoffs were: total time spent talking during stranger and peer components combined - less than $1 \mathrm{~min}$; total time within arm's length of mother during stranger and peer components combined - greater than $1 \mathrm{~min}$; total time spent staring at peer - greater than 2 min; frequency of approach to stranger - one or less; frequency of approach to peer - one or less (Rapee, Kennedy, Ingram, Edwards, \& Sweeney, 2005). Coding was conducted by postgraduate students in psychology, trained by the first author, who were blind to participants' STSC scores and diagnoses. Interrater reliability for observed $\mathrm{BI}$ was determined by having a second trained coder independently score the videotapes for $25 \%$ of the sample. The inter-rater reliability for number of cutoffs exceeded was ICC $=.91$ and for overall BI classification base on observation was kappa $=.79$.

Child anxiety disorders. All mothers were interviewed using the Anxiety Disorders Interview Schedule for DSM-IV, Parent Version (ADIS-P; Silverman \& Albano, 1996). At baseline, items referring to school were changed to 'preschool.' Previous research has shown that the ADIS-P can be reliably used to diagnose anxiety disorders in preschool children (Rapee et al., 2005). Diagnoses and Clinical Severity Ratings (CSRs on a scale of 0-8) were assigned by graduate students in psychology or qualified clinical psychologists trained by the first author, who were unaware of the child's group membership. Diagnoses were based on the criteria set out by the DSM-IV (American Psychiatric Association, 1994) and were only considered 'clinical' if the CSR was four or greater. As a method of assessing anxiety severity, number of anxiety diagnoses was used. A total of 44 cases (22\%) were coded by a second clinician from videotape. Interrater agreement was as follows: presence of clinical anxiety diagnosis (kappa $=.86)$, number of anxiety diagnoses $($ ICC $=.90)$. Reliability 
for individual diagnoses ranged from .77 to .81 . There were no gender differences in child anxiety status for the entire sample, $\chi^{2}(1, N=202)=0.18, p=.67$, or for the BI group independently, $\chi^{2}(1, N=102)=0.79, p=.38$.

Child anxiety symptoms. Mothers completed the Preschool Anxiety Scale, adapted from the Spence Children's Anxiety Scale (PAS; Spence, Rapee, McDonald, \& Ingram, 2001). The PAS contains 28 items that provide an overall measure of child anxiety as well as five specific aspects of child anxiety including generalised anxiety, separation anxiety, social phobia, physical injury fears, and obsessive-compulsive (scores range from 0 to 128). The measure has good construct validity, satisfactory internal consistency and good crossinformant and test-retest reliability (Spence et al., 2001). Internal consistency in this sample was as follows: Cronbach's alpha $=.93$. There were no significant gender differences in total anxiety scores on the PAS, $t(196)=1.54, p=.13$.

Maternal anxiety disorders. At baseline, mothers were interviewed with the Anxiety Disorders Interview Schedule for DSM-IV (DiNardo, Brown, \& Barlow, 1994) to assess current and lifetime Axis 1 diagnoses. Diagnoses and Clinical Severity Ratings were assigned by graduate students in psychology or qualified clinical psychologists trained by the first author, who were unaware of the child's group membership and anxiety status. Diagnoses were based on the criteria set out by the DSM-IV (APA, 1994) and were only considered 'clinical' if the CSR was four or greater. As a measure of anxiety severity number of clinical anxiety diagnoses was used. A total of 20 cases (10\%) were coded by a second clinician from videotape. Interrater agreement was as follows: any current anxiety diagnosis (kappa = .76), any lifetime (including current and past) anxiety diagnosis (kappa $=.78$ ), number of current anxiety diagnosis (ICC $=.85)$, number of lifetime anxiety diagnoses $($ ICC $=.67)$. Inter-rater agreement for a current diagnosis of the main anxiety disorders ranged from .77 - 1 . 
Maternal and paternal anxiety symptoms. Mother's and fathers anxiety symptoms were assessed using the Anxiety subscale of the Depression, Anxiety and Stress Scale (DASS21; Lovibond \& Lovibond, 1995). The DASS is a self-report measure of anxiety and depressive symptoms that asks participants to rate how they feel 'generally'. Participants rate 21 items, seven of which form the anxiety subscale, using a scale from zero (does not apply to me at all) to three (applies to me very much). The DASS-21 has good factor structure, concurrent validity and internal consistency (Antony, Bieling, Cox, Enns, \& Swinson, 1998). In the present sample the internal consistency of the DASS was as follows: fathers (Cronbach's alpha $=.89) ;$ mothers (Cronbach's alpha $=.88$ ).

\section{Overinvolvement and Negativity.}

Parent Protection Scale. The Parent Protection Scale was used to assess specific parenting behaviors related to child autonomy and parental overprotection (Thomasgard, Metz, Edelbrock, \& Shonkoff, 1995). The PPS contains 25 items (on a scale from zero to three) and four subscales: Supervision, Separation, Dependence and Control. The Control scale was of greatest interest to the current study. The PPS has shown adequate internal reliability, re-test reliability, criterion and content validity (Thomasgard \& Metz, 1999; Thomasgard et al., 1995). The internal consistency in this sample was Cronbach's alpha = .65 .

Speech preparation task. Mothers were observed interacting with their child during a three minute speech preparation task, adapted from Hudson and Rapee (2001). This task has been shown to reliably induce mild stress in participants. Children were asked to prepare a 1-minute speech and mothers were asked to provide support but only to provide help if they felt their child really needed it. The experimenter then left the room for 3 
minutes before returning and asking the child to stand and tell their story. The preparation time was videotaped and parental behaviour was coded.

Coders watched the entire interaction and then rated the parent's behaviour using six scales, each consisting of a nine-point continuum. The involvement factor consisted of the following global scales (i) general degree of mother's involvement, (ii) degree of unsolicited help, (iii) degree to which the mother directs the child's speech. The involvement factor (a mean of the three scales) represented the overall measure of the degree of help the parent gave during the task. The developmental level of the child and the amount of help that was therefore required was taken into account when judging evidence of overinvolved behaviour in the mother. The negativity factor assessed the degree of parental warmth during the interaction and comprised the following subscales (i) general mood atmosphere of the interaction, (ii) mother's degree of positive affect, and (iii) mother's degree of verbal and non-verbal encouragement and criticism. The negativity rating was based on a mean of the above three scales. The involvement and negativity factors represent theoretically constructed and empirically tested factors (Hudson \& Rapee, 2001).

All of the speech preparation tasks were coded by two postgraduate students in psychology, trained by the first author in the coding system until $80 \%$ accuracy was reached. Both coders were unaware of participants' diagnostic status. The reliability for the average of these ratings was ICC $=.94$ for the overinvolvement factor and ICC $=.73$ for the negativity factor. The average ratings of these two coders were used in analyses, with the exception of eight participants whose ratings were discrepant by more than two points. These interactions were coded again by the first author who decided on a final value taking into account the coders' initial responses. 
Five Minute Speech Sample. The Five Minute Speech Sample (FMSS) task was conducted and coded according to the method described by Magana et al. (1986). Parents were asked to describe their child and their relationship for five minutes without interruption. The speech samples were videotaped and transcribed. Two measurements were taken from the FMSS: Criticism and Over-involvement. A high criticism rating was assigned on the basis of one or more criticisms, a negative relationship rating, or a negative initial statement. A high over-involvement rating was assigned on the basis of reports of self-sacrificing or overprotective behaviour. The first author was trained and certified as a reliable rater by Sybil Zaden of U.C.L.A. and coded 48 transcripts. The first author trained the primary coder until $80 \%$ agreement was reached. Inter-rater reliability was as follows:

Overinvolvement (kappa $=.63)$, Criticism (kappa $=.96)$.

Attachment. Child-mother attachment was assessed using the preschool version of the Strange Situation procedure (Cassidy \& Marvin, 1992). Similar to the infant version of the Strange Situation (Ainsworth, Blehar, Waters, \& Wall, 1978) it consists of eight episodes of separation and reunion between mother and child, including an episode where the child plays in the room by themselves for 3 minutes and two episodes where the stranger is also present, one of these in the company of the mother.

Children were classified as either securely (B) or insecurely (insecure-avoidant (A), insecure-ambivalent (C), disorganised-controlling (D) or insecure-other) attached following observational coding of videotaped interactions by one of two certified coders trained in the Cassidy-Marvin (Macarthur) Preschool Attachment Classification System (Cassidy \& Marvin, 1992). For the purposes of data analysis, children classified as insecure-other were combined with disorganised-controlling to form a single D group. Reliability was established 
by having both coders independently code 42 cases. Agreement for classification into one of the four groups was kappa $=.74$.

\section{Procedure}

Macquarie University Human Ethics Committee approved the methods of the study. Following the initial screen using the parent-reported STSC, children meeting entry criteria were invited to take part in the full study. After a description of the study, mothers provided written informed consent for themselves and their children. The children provided assent to the study procedures. Families were reimbursed $\$ 50$ plus a small gift for their child. Parents and children visited the university for two 2-hour sessions during which all baseline assessments outlined above were completed. Additional questionnaires and observed tasks were also completed during the baseline session that are not presented here.

\section{Data Preparation and Analysis}

Multiple methods were used to assess the broad constructs of overinvolvement and negativity. Overinvolvement was measured using the Parent Protection Scale, the FMSS and the speech preparation task. To construct a single overinvolvement variable, the overinvolvement variable for each of these measures was converted to a z-score and the mean of the three measures was computed. Similarly, to construct a single negativity variable, the criticism variable from the FMSS and the negativity variable from the speech preparation task were converted into z-scores and the mean of the mean of the two measures was computed.

Due to technical problems with recording equipment, missed responses in questionnaires or the unavailability of fathers, there was a small amount of missing data. The analyses were conducted with the following family environment variables, the number in brackets shows the number of cases with complete data for each variable: 
overinvolvement (202), negativity (201), maternal current anxiety diagnosis (202), maternal lifetime anxiety diagnosis (202), maternal number of current diagnoses (202), maternal number of lifetime anxiety diagnoses (202), maternal anxiety symptoms as reported on the DASS (201), paternal anxiety symptoms as reported on the DASS (186) and an attachment variable representing the four attachment classifications described above (197). Child anxiety is represented by three variables: presence of clinical anxiety diagnosis (202), number of clinical anxiety diagnoses (202) and PAS score (198). Analyses are conducted with all available data.

Based on behaviour during the laboratory assessment of $\mathrm{BI}, 92$ participants were classified as inhibited and 110 participants as uninhibited. Classifications were in agreement with the original parent-report groups for $74 \%$ of participants. All analyses were therefore conducted initially using the parent-report groups and then conducted again using only those participants whose parent-report classification was consistent with their laboratorybased classification. Where differences in significance were found, these are reported. For all analyses including comparisons of temperament groups, the analyses were conducted with ethnicity controlled for. No significant effect of ethnicity was found for any of the analyses and no difference in the overall pattern of results was found when ethnicity was included. For simplicity the results are therefore reported without ethnicity.

Scores on the baseline PAS, mother-report DASS Anxiety scale and father-report DASS Anxiety scale were positively skewed and were successfully transformed using a square root transformation.

\section{Results}

\section{BI and Anxiety}


Table 1 shows the prevalence rates for anxiety diagnoses in the BI group and BUI group. Chi-squared analyses were used to compare prevalence rates between temperament groups. Where number of anxiety diagnoses was the dependent variable, negative binomial regression was used to be consistent with the distribution of the data. T-tests were conducted to compare temperament groups on PAS score. A Bonferroni-adjusted p-value of $0.006(0.05 / 8)$ was used to establish statistical significance. Effect size estimates are included as appropriate.

\section{[Insert Table 1 here]}

In comparison to the BUI group, the BI group were significantly more likely to meet criteria for an anxiety disorder and had a higher number of anxiety diagnoses. Significantly higher prevalence rates of Social Anxiety Disorder, Specific Phobia and Separation Anxiety Disorder were found in the BI group compared to the BUI group. The difference between temperament groups on Generalised Anxiety Disorder did not reach significance at the adjusted $p$-value. The total PAS score for the BI group $(\mathrm{M}=35.99, \mathrm{SD}=16.02)$ was significantly greater than the total score for the BUI group $(M=11.36, S D=9.40), t(196)=-$ $13.51, p<0.001, d=1.92$. When these analyses were conducted with the subsample of participants whose parent report BI status and observed BI status were consistent, the same patterns of significance were found.

\section{BI and Family Risk Factors}

Table 2 displays each family risk factor variable for the BI group and BUI group. To examine group differences, chi-squared analyses, t-tests and negative binomial regressions were conducted as appropriate. Bonferroni-adjusted $p$-values for statistical significance were as follows: maternal anxiety $p<.008(.05 / 6)$; parenting $p<.025(.05 / 2)$; attachment $p$ $<0.05$ (no adjustment necessary). A significant difference between the temperament groups 
was found on: maternal current anxiety diagnoses, maternal lifetime anxiety diagnoses, number of current maternal anxiety diagnoses, maternal anxiety symptoms, overinvolvement, and negativity. In addition, significant differences were found between temperament groups on ambivalent attachment, with inhibited children more likely to be classified as having ambivalent attachment than uninhibited children. No significant differences were found between temperament groups for paternal anxiety symptoms or number of maternal lifetime anxiety diagnoses. These findings were consistent when the sample was limited to only those participants whose BI classifications on parent report and observation were in agreement. The only exception to this was differences between temperament groups on negativity, which did not reach significance using the smaller sample, $\mathrm{t}(148)=-1.94, p=.05, d=.32$.

\section{[Insert Table 2 here]}

\section{Family Risk Factors, BI and Anxiety}

In the following analyses, the association between child anxiety and each of the following was examined: (1) temperament; (2) each family risk factor (Overinvolved Parenting, Negative parenting, Attachment, and Maternal Anxiety); (3) the interaction between each family risk factor and temperament. The continuous independent variables were centred prior to these analyses. The presence/absence of a clinical anxiety diagnosis and the total PAS score were the dependent variables. The results for each are presented in turn. For each set of analyses the Bonferroni-adjusted $p$-values for statistical significance were as follows: maternal anxiety analyses $p<.008(.05 / 6)$; parenting analyses $p<.025$ (.05/2); attachment analysis $p<0.05$ (no adjustment necessary).

\section{Presence of clinical anxiety diagnosis.}


To examine the additive and interactive effects of $\mathrm{BI}$ and family environment factors, logistic regression was used. For each analysis, temperament group was entered initially into the model. Subsequently, the variable representing the family factor of interest was entered, and finally the interaction between temperament and the family environment factor was entered. None of the interaction terms were statistically significant $(p>.1)$. A significant main effect of temperament group was found for all analyses $(p<.0001)$. The effect of each family environment factor, after controlling for the effect of temperament group, is shown in Table 3. This shows that, after controlling for the significant main effect of temperament group, there was a significant effect of maternal current anxiety diagnosis, number of current maternal anxiety diagnoses and number of maternal lifetime diagnoses, demonstrating additive effects. No significant effect of any of the other family environment factors was found, after controlling for the effect of temperament.

[Insert Table 3 here]

The only significant predictors of child anxiety diagnosis were maternal anxiety and temperament group. Together maternal current anxiety diagnosis (the maternal anxiety variable with the largest effect size) and temperament group correctly predicted the presence of an anxiety diagnosis in $81 \%$ of participants and correctly predicted the absence of an anxiety diagnosis in $75 \%$ of participants.

When the analyses were conducted using only those participants whose parent reported $\mathrm{BI}$ status and observation of $\mathrm{BI}$ were consistent, the pattern of results were consistent with the exception that no significant effect of number of maternal lifetime anxiety diagnoses, $b=.20, S E=.15$, Wald $=1.87, d f=1, p=.17, O R=1.22$, was found.

\section{PAS scores.}


The general linear model procedure (GLM) was used to examine the relationship between family factors, $\mathrm{BI}$ and the interaction between each family factor and $\mathrm{BI}$ with child anxiety symptoms. For each analysis temperament group was initially entered into the model. Subsequently, the variable representing the family factor of interest was entered and finally the interaction between temperament and the family environment factor was entered. Type I sums of squares was used. No significant interactions were found between temperament group and any of the family factor variables $(p>.1)$. For all analyses the main effect of temperament group was significant $\left(p<0.0001\right.$; partial $\left.\eta^{2}>.4\right)$. The effect of each family environment factor after controlling for temperament group is shown in Table 4. In addition to the significant main effect of temperament group, a significant relationship between child anxiety symptoms and maternal current anxiety disorder, maternal lifetime anxiety disorder, number of maternal current anxiety disorders, number of maternal lifetime anxiety disorders, and maternal anxiety symptoms, was found. In addition, there was a significant main effect of maternal negativity. No significant effect of overinvolvement, attachment style, or paternal anxiety symptoms was found. The results were consistent when the sample was limited to only those participants whose $\mathrm{BI}$ classifications on parent report and observation were in agreement.

To examine the relative contribution of all the significant predictors found above (temperament group, maternal anxiety, and maternal negativity) a GLM analysis was conducted including all of these variables in a single model using type III marginal sums of squares. As no significant interactions were found, no interactions were included. Maternal current anxiety diagnosis was used to represent maternal anxiety as this variable received the highest effect size of the diagnostic variables above. A significant main effect of maternal negativity, $\mathrm{F}(1,193)=7.29, \mathrm{MSE}=12.04, p=.008\left(\right.$ partial $\left.\eta^{2}=.036\right)$, maternal 
current anxiety disorder, $\mathrm{F}(1,193)=33.78, \mathrm{MSE}=55.79, p<.0001\left(\right.$ partial $\left.\eta^{2}=.149\right)$, and temperament group, $F(1,193)=158.13, \mathrm{MSE}=261.20, p<.0001\left(\right.$ partial $\left.\eta^{2}=.45\right)$, were found. Together, maternal current anxiety diagnoses, temperament group and maternal negativity accounted for $58 \%$ of the variance in PAS score.

To examine whether family factors might influence the association between temperament and anxiety differently according to child gender, we conducted the above analyses including three way environment $x$ temperament $x$ gender interactions. None of these interactions were significant $(p>.1)$.

\section{Discussion}

The aim of this research was to examine the relationship between $\mathrm{BI}$, family environment and anxiety in a sample of preschool children, with a specific focus on the interactive and additive effects of child temperament and family environment. A number of hypotheses were made based on the findings of previous research and relevant etiological models of child anxiety. First, it was hypothesised that BI would be significantly associated with child anxiety and that this association would be particularly strong for social anxiety. The results provided some support for this initial hypothesis; children in the BI group had significantly higher prevalence rates of anxiety disorders and parent-reported symptoms, but this was not specific to Social Anxiety Disorder; significantly higher rates were also found for Specific Phobia and Separation Anxiety Disorder. These results are consistent with previous research demonstrating that $\mathrm{BI}$ is associated with increased anxiety in children (Chronis-Tuscano et al., 2009; Schwartz et al., 1999). Importantly, however, these results provide the first evidence that BI may be a related to a range of childhood anxiety disorders rather than just Social Anxiety Disorder, as has been suggested in previous research 
(Chronis-Tuscano et al., 2009; Muris et al., 2010). It will be important to explore this finding further in future research using a longitudinal methodology.

The second hypothesis was that the BI group, relative to BUI group, would experience more adverse family environments across the environmental factors assessed. The results also supported this hypothesis; high BI was associated with elevated rates of maternal anxiety disorders and symptoms, more overinvolved parenting, more negative parenting and higher rates of ambivalent attachment. The only family environment risk factor assessed that was not associated with BI was paternal anxiety symptoms. These results are also in keeping with previous findings suggesting a relationship between $\mathrm{BI}$ and overinvolvement (Rubin et al., 1999), negativity (Hirshfeld-Becker et al., 1997), maternal anxiety (Biederman et al., 1993) and attachment (Shamir-Essakow et al., 2005).

As discussed previously, there are a number of ways in which temperament and family environment may be associated with child anxiety. In the present research we were interested in whether family environment factors accounted for additional variance in child anxiety, after controlling for child temperament (additive effect of family environment) and whether family environment factors interacted with temperament to account for variance in child anxiety (interactive effects). The results provided no evidence for temperament by family environment interactions. There was, however, consistent evidence that parentreported $\mathrm{BI}$ and maternal anxiety were both independently associated with child anxiety diagnoses. Furthermore, the results suggest that maternal negativity may also be significantly related to child anxiety, even after controlling for $\mathrm{BI}$ and maternal anxiety. In contrast, overinvolvement, attachment and paternal anxiety symptoms were not significantly associated with child anxiety when the relationship between $\mathrm{BI}$ and anxiety was 
taken into account. These findings suggest that adverse family environment may add to anxiety risk equally in both temperamentally at risk and not at risk children.

The lack of significant interactions between temperament and family environment factors is not in keeping with recent theoretical models (Hudson \& Rapee, 2005; Vasey \& Dadds, 2001) but is consistent with the small number of previous studies to have examined $\mathrm{BI}$ and environmental risk factors. There are a number of possible explanations for the lack of significant interactions. First, as discussed, children high on BI may not be any more vulnerable to adverse environments than those low on $\mathrm{BI}$ and these risk factors might instead have additive effects on child anxiety. Alternatively, the outcome of interactions between temperament and environment may not be expressed until later in development, perhaps when children encounter stressors such as starting school. If this is the case then longitudinal follow-ups across childhood will be required for the effect of interactions to be observed. Similarly, it is possible that temperament, as assessed at different developmental stages, such as infancy, or stable temperament across early childhood, might interact with family environment factors. Finally, it is also possible that the lack of significant interactions is an artefact of the difficulty finding interactions in non-experimental research (See McClelland \& Judd, 1993 for a discussion).

Although no significant interaction with $\mathrm{BI}$ was found, the results provided consistent evidence for a relationship between maternal anxiety and child anxiety, even after controlling for child temperament. This relationship was particularly strong for current maternal anxiety, as contrasted with lifetime maternal anxiety. This might suggest that maternal anxiety not only infers genetic risk for anxiety but also acts as an environmental risk factor for child anxiety, possibly via the modelling of anxious behaviour, verbal communication of threat information and encouragement of avoidance (Barrett et al., 1996; 
Field et al., 2008; Murray et al., 2008). However, it is also possible that mothers who had a current anxiety diagnosis had more chronic or severe anxiety than those who had met criteria for an anxiety disorder in the past but had recovered. Further research more closely comparing these groups will be important to clarify the relationship between maternal anxiety and child anxiety.

In contrast to the strong support for a relationship between maternal anxiety and child anxiety, no significant relationship between paternal anxiety and child anxiety, or BI, was found. This finding is somewhat surprising in light of recent etiological models emphasising the role of fathers in the development of child anxiety (Bogels \& Phares, 2008). Previous research has been mixed with regards the relationship between paternal anxiety and child anxiety with some research finding a relationship between anxiety in fathers and anxiety in children (Muris et al., 2010), and other research finding no relationship (McClure, Brennan, Hammen, \& Le Brocque, 2001). It seems likely that the effect of paternal anxiety on child anxiety might depend on the role the father plays in the child's care. In the circumstance where the child's mother is their primary caregiver, the environmental effects of maternal anxiety may be stronger than the effects of paternal anxiety. It is possible that a relationship between paternal anxiety and child anxiety might have been found if full diagnostic interviews had been conducted. It will be useful, therefore, for future research to include diagnostic measures of paternal anxiety as well as maternal anxiety and also to record the extent to which each parent is involved in the child's care.

After controlling for maternal anxiety and BI, there was a significant relationship between maternal negativity and child anxiety symptoms. It is possible therefore that maternal negativity may affect child anxiety. Previous research has, however, yielded inconsistent evidence for a causal relationship (McLeod et al., 2007; Wood et al., 2003). 
Alternatively, it is possible that mothers tend to be more negative when talking about their child, and interacting with their child, if their child is anxious. This may be exaggerated when the parent-child interaction is assessed in an anxiety provoking situation. Future longitudinal research will provide further insight into this relationship and the direction of this effect.

The results of this study provide important insights into the relationship between risk factors typically studied in isolation and between these risk factors and child anxiety. However, the limitations of the study should be considered. First, the cross-sectional design means that it is not possible to disentangle patterns of cause and effect. For example, it remains possible that parenting an anxious child could lead to an increase in maternal anxiety. It will be important for future research to use a thorough methodology, as exemplified here, to conduct longitudinal research into the causes of child anxiety. Longitudinal research will also provide an opportunity for mediation pathways to be examined. For example, BI could affect parenting, which might affect future anxiety risk. Second, the main focus of the present research was on mother-child interactions and mother-child relationships. However, as highlighted in a recent review (Bogels \& Phares, 2008), fathers may also play a role in the development of child anxiety. This represents an exciting area for future research. Third, the majority of the participants were from middle class families. The extent to which the present findings generalise to other populations is not currently clear. Finally, it was not possible to include all risk factors that have been associated with $\mathrm{BI}$ and child anxiety. Other risk factors that may be of particular importance for future research to consider are parental depression, effortful control and life events.

Although it is not possible to examine causal pathways in the present research, the findings clearly demonstrate that inhibited preschool children are likely to be exposed to a variety of environmental risk factors and that certain family environment factors may affect 
anxiety over and above child temperament. On the basis of the present findings, it may be particularly important to assess maternal anxiety, temperament and maternal negativity when seeking to identify children at-risk for elevated anxiety. However, longitudinal data is essential to clarify the factors that predict change in anxiety over time. The findings have implications for early intervention programs aimed at reducing anxiety risk in this group. Rather than specifically focusing on inhibition and reactivity to novelty, it may be necessary to target a range of risk factors, in particular those that might play a role in the maintenance of $\mathrm{BI}$ such as overinvolved parenting, in order to affect anxiety risk in this group. 


\section{References}

Ainsworth, M. D. S., Blehar, M. C., Waters, E., \& Wall, S. (1978). Patterns of attachment: Psychological study of the strange situation. Hillsdale, NJ: Erlaum.

American Psychiatric Association. (1994). Diagnostic and statistical manual of mental disorders (4th ed.). Washington, DC: American Psychiatric Association.

Antony, M. M., Bieling, P. J., Cox, B. J., Enns, M. W., \& Swinson, R. P. (1998). Psychometric properties of the 42-item and 21-item versions of the Depression Anxiety Stress Scales in clinical groups and a community sample. Psychological Assessment, 10, 176181. doi:10.1037//1040-3590.10.2.176

Barrett, P. M., Fox, T., \& Farrell, L. J. (2005). Parent-child interactions with anxious children and with their siblings: an observational study. Behaviour Change, 22, 220-235. doi: 10.1375/bech.22.4.220

Barrett, P. M., Rapee, R. M., Dadds, M. M., \& Ryan, S. M. (1996). Family enhancement of cognitive style in anxious and aggressive children. Journal of Abnormal Child Psychology, 24, 187-203. doi: 10.1007/BF01441484

Bayer, J. K., Sanson, A. V., \& Hemphill, S. A. (2006). Parent influences on early childhood internalizing difficulties. Journal of Applied Developmental Psychology, 27, 542-559. doi: 10.1016/j.appdev.2006.08.002

Biederman, J., Faraone, S. V., Hirshfeld-Becker, D. R., Friedman, D., Robin, J. A., \& Rosenbaum, J. F. (2001). Patterns of psychopathology and dysfunction in high-risk children of parents with panic disorder and major depression. The American Journal of Psychiatry, 158, 49-57. doi: 10.1176/appi.ajp.158.1.49

Biederman, J., Rosenbaum, J. F., Bolduc-Murphy, E. A., Faraone, S. V., Chaloff, J., Hirshfeld, D.R., Kagan, J. (1993). A 3-year follow-up of children with and without behavioral inhibition. Journal of the American Academy of Child and Adolescent Psychiatry, 32, 814-821. doi: 10.1097/00004583-199307000-00016

Bogels, S. M., \& Phares, V. (2008). Fathers' role in the etiology, prevention and treatment of child anxiety: A review and new model. Clinical Psychology Review, 28, 539-558. doi: 10.1016/j.cpr.2007.07.011 
Brumariu, L. E., \& Kerns, K. A. (2010). Parent-child attachment and internalizing symptoms in childhood and adolescence: A review of empirical findings and future directions. Development and Psychopathology, 22, 177-203. doi: 10.1017/S0954579409990344

Cartwright-Hatton, S., Roberts, C., Chitsabesan, P., Fothergill, C., \& Harrington, R. (2004). Systematic review of the efficacy of cognitive behaviour therapies for childhood and adolescent anxiety disorders. British Journal of Clinical Psychology, 43, 421-436. doi: $10.1348 / 0144665042388928$

Cassidy, J., \& Marvin, R. S. (1992). Attachment organization in preschool children: Procedures and coding manual (4 ed.). University of Virginia: Unpulished manuscript.

Chronis-Tuscano, A., Degnan, K. A., Pine, D. S., Perez-Edgar, K., Henderson, H. A., Diaz, Y. (2009). Stable early maternal report of behavioral inhibition predicts lifetime social anxiety disorder in adolescence. Journal of American Academy of Child and Adolescent Psychiatry, 48, 928-935 910.1097/CHI.1090b1013e3181ae1009df.

Cooper, P. J., Fearn, V., Willetts, L., Seabrook, H., \& Parkinson, M. (2006). Affective disorder in the parents of a clinic sample of children with anxiety disorders. Journal of Affective Disorders, 93, 205-212. doi: 10.1016/j.jad.2006.03.017

Costello, E., Mustillo, S., Erkanli, A., Keeler, G., \& Angold, A. (2003). Prevalence and development of psychiatric disorders in childhood and adolescence. Archives of General Psychiatry, 60, 837-844. doi: 10.1001/archpsyc.60.8.837

Degnan, K. A., Henderson, H. A., Fox, N. A., \& Rubin, K. H. (2008). Predicting social wariness in middle childhood: The moderating roles of childcare history, maternal personality and maternal behavior. Social Development, 17, 471-487. doi: 10.1111/j.14679507.2007.00437.x

Degnan, K. A., Almas, A. N., \& Fox, N. A. (2010). Temperament and the environment in the etiology of childhood anxiety. Journal of Child Psychology and Psychiatry, 51, 497517. doi: http://dx.doi.org/10.1111/j.1469-7610.2010.02228.x

Dilalla, L. F., Kagan, J., \& Reznick, J. S. (1994). Genetic etiology of behavioral inhibition among 2-year-old children. Infant Behavior and Development, 17, 405-412. doi: 10.1016/0163-6383(94)90032-9 
DiNardo, P. A., Brown, T. A., \& Barlow, D. H. (1994). Anxiety Disorders Interview Schedule: Lifetime Version (ADIS-IV-L). Client Interview Schedules. Oxford, UK: Oxford University Press.

Edwards, S. L., Rapee, R. M., \& Kennedy, S. (2010). Prediction of anxiety symptoms in preschool-aged children: Examination of maternal and paternal perspectives. Journal of Child Psychology and Psychiatry, 51, 313-321. doi: 10.1111/j.14697610.2009.02160.x

Field, A. P., Lawson, J., \& Banerjee, R. (2008). The verbal threat information pathway to fear in children: The longitudinal effects on fear cognitions and the immediate effects on avoidance behavior. Journal of Abnormal Psychology, 117, 214-224. doi: 10.1037/0021-843X.117.1.214

Fox, N. A., Henderson, H. A., Marshall, P. J., Nichols, K. E., \& Ghera, M. M. (2005). Behavioral inhibition: Linking biology and behavior within a developmental framework. Annual Review of Psychology, 56, 235-262. doi: 10.1146/annurev.psych.55.090902.141532

Garcia-Coll, C., Kagan, J., \& Reznick, J. (1984). Behavioral Inhibition in young children. Child Development, 55, 1005-1019. doi: 10.2307/1130152

Hirshfeld-Becker, D. R., Biederman, J., Brody, L., \& Faraone, S. V. (1997). Associations between expressed emotion and child behavioral inihibition and psychopathology: $A$ pilot study. Journal of the American Academy of Child and Adolescent Psychiatry, 36, 205-213. doi: 10.1097/00004583-199702000-00011

Hudson, J. L., \& Rapee, R. M. (2001). Parent-child interactions and anxiety disorders: An observational study. Behaviour Research and Therapy, 39, 1411-1427. doi: 10.1016/S0005-7967(00)00107-8

Hudson, J. L., \& Rapee, R. M. (2004). From temperament to disorder: An etiological model of Generalized Anxiety Disorder. In R. G. Heimberg, C. C. Turk \& D. S. Menin (Eds.), Generalized Anxiety Disorder: Advances in Research and Practice. New York: Guildford Press.

Kagan, J., Reznick, J., \& Gibbons, J. (1989). Inhibited and uninhibited types of children. Child Development, 60, 838-845. doi: 10.2307/1131025

Lieb, R., Wittchen, H.-U., Hofler, M., Fuetsch, M., Stein, M. B., \& Merikangas, K. R. (2000). Parental psychopathology, parenting styles, and the risk of social phobia in offspring: 
A prospective-longitudinal community study. Archives of General Psychiatry, 57, 859866. doi: doi:10.1001/archpsyc.57.9.859

Lovibond, S. H., \& Lovibond, P. F. (1995). Manual for the Depression Anxiety Stress Scales. (2nd ed.). Sydney: Psychology Foundation.

Magana, A. B., Goldstein, M. J., Karno, M., Miklowitz, D. J., Jenkins, J., \& Falloon, I. R. H. (1986). A brief method for assessing expressed emotion in relatives of psychiatric patients. Psychiatry Research, 17, 203-212. doi: 10.1016/0165$1781 \% 2886 \% 2990049-1$

Maxwell, S. E., \& Cole, D. A. (2007). Bias in cross-sectional analyses of longitudinal mediation. Psychological Methods, 12, 23-44. doi:10.1037/1082-989X.12.1.23

McClelland, G. H., \& Judd, C. M. (1993). Statistical difficulties of detecting interactions and moderator effects. Psychological Bulletin, 114, 376-390. doi: 10.1037/00332909.114.2.376

McClure, E. B., Brennan, P. A., Hammen, C., \& Le Brocque, R. M. (2001). Parental anxiety disorders, child anxiety disorders, and the perceived parent-child relationship in an Australian high-risk sample. Journal of Abnormal Child Psychology, 29, 1-10. doi: 10.1023/A:1005260311313

McLeod, B. D., Wood, J. J., \& Weisz, J. R. (2007). Examining the association between parenting and childhood anxiety: A meta-analysis. Clinical Psychology Review, 27, 155-172.

Moss, E., Smolla, N., Cyr, C., Dubois-Comtois, K., Mazzarello, T., \& Berthiaume, C. (2006). Attachment and behavior problems in middle childhood as reported by adult and child informants. Development and Psychopathology, 18, 425-444. doi: $10.1017 /$ S0954579406060238

Muris, P., van Brakel, A. M. L., Arntz, A., \& Schouten, E. (2010). Behavioral inhibition as a risk factor for the development of childhood anxiety disorders: A longitudinal study. Journal of Child and Family Studies. doi: 10.1007/s10826-010-9365-8

Murray, L., de Rosnay, M., Pearson, J., Bergeron, C., Schofield, E., Royal-Lawson, M. (2008). Intergenerational transmission of social anxiety: The role of social referencing processes in infancy. Child Development, 79, 1049-1064. doi: 10.1111/j.14678624.2008.01175.x 
Prior, M., Smart, D., Sanson, A., \& Oberklaid, F. (2000). Does shy-inhibited temperament in childhood lead to anxiety problems in adolescence? Journal of the American Academy of Child and Adolescent Psychiatry, 39, 461-468. doi: 10.1097/00004583200004000-00015

Rapee, R. M. (1997). Potential role of childrearing practices in the development of anxiety and depression. Clinical Psychology Review, 17, 47-67. doi: 10.1016/S02727358(96)00040-2

Rapee, R. M., Kennedy, S., Ingram, M., Edwards, S., \& Sweeney, L. (2005). Prevention and early intervention of anxiety disorders in inhibited preschool children. Journal of Consulting and Clinical Psychology, 73, 488-497.

Rubin, K. H., Burgess, K. B., \& Hastings, P. D. (2002). Stability and social-behavioral consequences of toddlers' inhibited temperament and parenting behaviors. Child Development, 73, 483-495. doi:10.1111/1467-8624.00419

Rubin, K. H., Nelson, L. J., Hastings, P., \& Asendorpf, J. (1999). The transaction between parents' perceptions of their children's shyness and their parenting styles. International Journal of Behavioral Development, 23, 937-958.

Sanson, A., Smart, D., Prior, M., Oberklaid, F., \& Pedlow, R. (1994). The structure of temperament from age 3 to 7 Years: Age, sex, and sociodemographic influences. Merrill-Palmer Quarterly, 40, 233-252.

Schwartz, C. E., Snidman, N., \& Kagan, J. (1999). Adolescent social anxiety as an outcome of inhibited temperament in childhood. Journal of the American Academy of Child \& Adolescent Psychiatry, 38, 1008-1015. doi: 10.1097/00004583-199908000-00017

Shamir-Essakow, G., Ungerer, J. A., \& Rapee, R. M. (2005). Attachment, behavioral inhibition, and anxiety in preschool children. Journal of Abnormal Child Psychology, 33, 131-143. doi: doi:10.1007/s10802-005-1822-2

Silverman, W. K., \& Albano, A. M. (1996). The Anxiety Disorders Interview Schedule for Children for DSM-IV: Child and Parent Versions. San Antonia, TX: Psychological Corporation.

Spence, S. H., Rapee, R., McDonald, C., \& Ingram, M. (2001). The structure of anxiety symptoms among preschoolers. Behaviour Research \& Therapy, 39, 1293-1316. doi: 10.1016/S0005-7967(00)00098-X 
Thomasgard, M., \& Metz, W. (1999). Parent-child relationship disorders: What do the child vulnerability scale and the parent protection scale measure? Clinical Pediatrics, 38, 347-356. doi: 10.1177/000992289903800605

Thomasgard, M., Metz, W., Edelbrock, C., \& Shonkoff, J. P. (1995). Parent-child relationship disorders: I. Parental overprotection and the development of the Parent Protection Scale. Journal of Developmental and Behavioral Pediatrics, 16, 244-250. doi: 10.1097/00004703-199508000-00006

van Brakel, A. M., Muris, P., Bogels, S. M., \& Thomassen, C. (2006). A multifactorial model for the etiology of anxiety in non-clinical adolescents: main and interactive effects of behavioral inhibition, Attachment and Parental Rearing. Journal of Child and Family Studies, 15, 569-579. doi: 10.1007/s10826-006-9061-x

van der Bruggen, C. O., Stams, G. J. J., \& Bogels, S. M. (2008). Research review: The relation between child and parent anxiety and parental control: A meta-analytic review. Journal of Child Psychology and Psychiatry, 49, 1257-1269. doi: 10.1111/j.14697610.2008.01898.x

Vasey, M. W., \& Dadds, M. R. (Eds.). (2001). The developmental psychopathology of anxiety. London: Oxford University Press.

Wood, J. J., McLeod, B. D., Sigman, M., Hwang, W.-C., \& Chu, B. C. (2003). Parenting and childhood anxiety: Theory, empirical findings, and future directions. Journal of Child Psychology and Psychiatry, 44, 134-151. doi: 10.1111/1469-7610.00106 
Table 1

Prevalence rates for anxiety diagnoses and mean number of anxiety diagnoses in the high $\mathrm{BI}$ (BI) and low BI (BUI) groups.

\section{$\mathrm{BI} \quad \mathrm{BUI} \quad$ Between group comparisons}

\begin{tabular}{|c|c|c|c|}
\hline Any anxiety disorder * & $73 \%$ & $17 \%$ & $\chi^{2}(1, N=202)=62.94, p<.0001, \phi=.56$ \\
\hline Social Anxiety Disorder * & $43 \%$ & $0 \%$ & $\chi^{2}(1, N=202)=55.15, p<.0001, \phi=.52$ \\
\hline Separation Anxiety Disorder * & $30 \%$ & $2 \%$ & $\chi^{2}(1, N=202)=29.782, p<.0001,, \phi=.39$ \\
\hline Specific Phobia* & $50 \%$ & $12 \%$ & $\chi^{2}(1, N=202)=33.98, p<.0001, \phi=.41$ \\
\hline Generalised Anxiety Disorder * & $12 \%$ & $3 \%$ & $\chi^{2}(1, N=202)=5.64, p=.02, \phi=.17$ \\
\hline Obsessive Compulsive Disorder & $2 \%$ & $2 \%$ & - \\
\hline Post Traumatic Stress Disorder & $2 \%$ & $0 \%$ & - \\
\hline Mean number of anxiety & 1.59 & 0.24 & $b=-1.896, S E=.26$, Wald $\chi^{2}(1, N=202)=$ \\
\hline \multirow[t]{2}{*}{ diagnoses * } & $(s d=$ & $(s d=$ & $53.167, p<.0001$ \\
\hline & 1.38) & $0.55)$ & \\
\hline
\end{tabular}

* denotes significant group difference after controlling for ethnicity at $p<0.05$. 
Table 2

Comparisons between in the high $B I(B I)$ and low $B I(B U I)$ groups on family risk factors.

BI

\section{BUI}

\begin{tabular}{|c|c|c|c|}
\hline \multicolumn{4}{|l|}{ Parental Anxiety } \\
\hline Maternal current anxiety disorder * & $50 \%$ & $28 \%$ & $\chi^{2}(1, N=202)=10.26, p=.001, \phi=.23$ \\
\hline Maternal lifetime anxiety disorder * & $73 \%$ & $50 \%$ & $\chi^{2}(1, N=202)=10.83, p=.001, \phi=.23$ \\
\hline \multirow[t]{2}{*}{ Mean number of maternal current anxiety disorders * } & 0.88 & 0.47 & $b=-.63, S E=.23$, Wald $\chi^{2}(1, N=202)=7.60, p=.006$ \\
\hline & $(1.15)$ & $(0.89)$ & \\
\hline \multirow[t]{2}{*}{ Mean number of maternal lifetime anxiety disorders } & 1.60 & 1.06 & $b=-.411, S E=.188$, Wald $\chi^{2}(1, N=202)=4.764, p=.029$ \\
\hline & $(1.57)$ & $(1.40)$ & \\
\hline \multirow[t]{2}{*}{ Mean maternal DASS Anxiety Scale * } & 2.95 & 1.92 & $\mathrm{t}(199)=-3.12, p=.002, d=.38$ \\
\hline & $(2.99)$ & $(2.36)$ & \\
\hline \multirow[t]{2}{*}{ Mean paternal DASS Anxiety Scale } & 1.71 & 1.94 & $\mathrm{t}(184)=1.20, p=.23, d=.11$ \\
\hline & $(2.13)$ & $(1.98)$ & \\
\hline
\end{tabular}




\begin{tabular}{|c|c|c|c|}
\hline \multicolumn{4}{|l|}{ Parenting Behaviour } \\
\hline \multirow[t]{2}{*}{ Overinvolvement ${ }^{\mathrm{a} *}$} & 0.14 & -0.14 & $\mathrm{t}(200)=-3.07, p=.002, d=.43$ \\
\hline & $(0.70)$ & $(0.59)$ & \\
\hline \multirow[t]{2}{*}{ Mean negativity score ${ }^{\mathrm{a}} *$} & 0.13 & -0.16 & $\mathrm{t}(199)=-3.03, p=0.003, d=0.42$ \\
\hline & $(0.70)$ & $(0.67)$ & \\
\hline Attachment & & & $\chi^{2}(3, N=197)=11.12, p=.01, \phi=.24$ \\
\hline Avoidant $-\mathrm{A}$ & $32.3 \%$ & $29.6 \%$ & $\chi^{2}(1, N=197)=.17, p=.68, \phi=.03$ \\
\hline Secure - B & $40 \%$ & $60 \%$ & $\chi^{2}(1, N=197)=4.30, p=.04, \phi=.15$ \\
\hline Ambivalent $-C^{*}$ & $12.1 \%$ & $1 \%$ & $\chi^{2}(1, N=197)=9.85, p=.002, \phi=.22$ \\
\hline Disorganised - D & $11.1 \%$ & $11.2 \%$ & $\chi^{2}(1, N=197)=.001, p=.98, \phi=.002$ \\
\hline
\end{tabular}

Note. Standard deviations are shown in brackets.

${ }^{a}$ Positive scores indicate greater overinvolvement/negativity.

* Significant between group differences, $p<0.05$ 


\section{Table 3}

The relationship between family environment factors and the presence of a clinical anxiety diagnosis after controlling for the effect of

temperament group.

\begin{tabular}{|c|c|c|c|c|c|c|}
\hline & $b$ & $S E$ & Wald & df & $p$ & OR \\
\hline \multicolumn{7}{|l|}{ Parental Anxiety } \\
\hline Maternal current anxiety disorder & 1.15 & 0.36 & 10.23 & 1 & $.001 *$ & 3.16 \\
\hline Maternal lifetime anxiety disorder & 0.78 & .36 & 4.56 & 1 & $.033^{\#}$ & 2.17 \\
\hline Number of maternal current anxiety disorders & 0.58 & .18 & 9.79 & 1 & $.002 *$ & 1.78 \\
\hline Maternal DASS Anxiety Scale & 0.45 & .19 & 5.41 & 1 & $.020^{\#}$ & 1.57 \\
\hline Paternal DASS Anxiety Scale & 0.09 & .21 & .19 & 1 & .67 & 1.10 \\
\hline \multicolumn{7}{|l|}{ Parenting Behaviour } \\
\hline \multicolumn{7}{|l|}{ Attachment } \\
\hline Attachment style & .46 & .37 & 1.56 & 1 & .21 & .63 \\
\hline
\end{tabular}

* Significant between group differences at Bonferroni-adjusted $p$-value. $\# p<0.05$ but not significant at Bonferroni-adjusted $p$-value. 
Table 4

The relationship between family environment factors and child anxiety symptoms after controlling for the effect of temperament group.

\begin{tabular}{|c|c|c|c|c|c|}
\hline & df & $\mathrm{F}$ & MSE & $p$ & partial $\eta^{2}$ \\
\hline \multicolumn{6}{|l|}{ Parental Anxiety } \\
\hline Maternal current anxiety disorder & 1,193 & 38.41 & 64.81 & $<.0001^{*}$ & .17 \\
\hline Maternal lifetime anxiety disorder & 1,193 & 26.46 & 46.84 & $<.0001^{*}$ & .12 \\
\hline Number of maternal current anxiety disorders & 1,193 & 36.64 & 62.02 & $<.0001^{*}$ & .16 \\
\hline Number of maternal lifetime anxiety disorders & 1,193 & 30.98 & 54.09 & $<.0001^{*}$ & .14 \\
\hline Maternal DASS Anxiety Scale & 1,192 & 41.64 & 69.59 & $<.0001^{*}$ & .18 \\
\hline Paternal DASS Anxiety Scale & 1,179 & 2.04 & 3.95 & .16 & .02 \\
\hline \multicolumn{6}{|l|}{ Parenting Behaviour } \\
\hline Overinvolvement & 1,193 & .40 & .81 & .39 & $<.01$ \\
\hline Negativity & 1,192 & 9.57 & 18.54 & $.002 *$ & .05 \\
\hline \multicolumn{6}{|l|}{ Attachment } \\
\hline Attachment style & 3,184 & .82 & 1.67 & .48 & .01 \\
\hline
\end{tabular}

* Significant between group differences at Bonferroni-adjusted $p$-value. 